\title{
Dos possíveis e impossíveis em psicanálise fora do consultório: Algumas questões
}

\author{
Of the possible and impossible in psychoanalysis outside the office: Some issues
}

\author{
Allan Martins Mohrr ${ }^{[a]}$, Luciana Albanese Valore ${ }^{[b]}$
}

\footnotetext{
${ }^{[a]}$ Mestre em Psicologia pela Universidade Federal do Paraná (UFPR), psicólogo no Núcleo de Acompanhamento Psicopedagógico e Assistência Estudantil, e no Núcleo de Apoio às Pessoas com Necessidades, Universidade Tecnológica Federal do Paraná (UTPR), Curitiba, PR - Brasil, e-mail: allan.mohr@gmail.com

${ }^{[b]}$ Doutora em Psicologia Escolar e do Desenvolvimento Humano pela Universidade de São Paulo (USP), professora associada do Departamento de Psicologia e diretora do Centro de Estudos e Assessoria em Psicologia e Educação da Universidade Federal do Paraná (CEAPE/ UFPR), Curitiba, PR - Brasil, e-mail: luvalore@uol.com.br
}

Recebido: $17 / 08 / 2010$ Received: 08/17/2010

Aprovado: 11/05/2011 Approved: 05/11/2011

\section{Resumo}

0 foco do presente artigo consiste naquilo que se convencionou denominar de Psicanálise Aplicada. A partir de um estudo teórico, objetiva-se analisar a possibilidade ou impossibilidade de se fazer Psicanálise fora dos consultórios. Especificamente, pretende-se delinear o que é a Psicanálise Aplicada e quais suas diferenças da então Psicanálise Pura, ou Psicanálise Livre, como denominada por Sigmund Freud em sua obra. Inicia-se este estudo com a conceituação própria de Psicanálise Aplicada, posteriormente, apresentam-se algumas discussões a respeito da prática psicanalítica em instituições, uma discussão acerca da instituição na qual a psicanálise é aplicada e do psicanalista enquanto aplicado à instituição. Finalmente, conclui-se com reflexões acerca da possibilidade ou impossibilidade da Psicanálise, ou melhor, dos psicanalistas, avançarem para fora do consultório e adentrarem as instituições com o objetivo de ouvir a subjetividade e sustentar um lugar de palavra para o sujeito (do inconsciente) ali, onde quer que ele se coloque, seja na escola, no hospital, ou em qualquer outra instituição social.

Palavras-chave: Psicanálise Aplicada. Subjetividade. Instituições.

\section{Abstract}

The focus of this paper is on what is conventionally termed Applied Psychoanalysis. Through a theoretical study, its objective is to analyze the possibility or impossibility of doing psychoanalysis outside the office. Specifically, it is intended to outline what applied psychoanalysis is and what are the differences from pure psychoanalysis, or free psychoanalysis, as termed by Sigmund Freud in his works. This study begins with the very concept of applied psychoanalysis; afterwards presenting some discussions on practical work in institutions, a discussion about the institution where psychoanalysis is applied and the psychoanalyst, where it may be applicable to the institution. Finally, it concludes with reflections on the possibility or impossibility of psychoanalysis, or rather, the psychoanalysts, moving out of the office and stepping into the institutions in order to listen to the subjectivity and to keep a place of talking for the subject (of the unconscious) there, wherever it is put, whether in school, hospital, or any other social institution.

Keywords: Applied psychoanalysis. Subjectivity. Institutions. 


\section{Introduç̃̃o}

Que a psicanálise nasceu da clínica propriamente dita, isso é um fato incontestável. Porém, que seu próprio criador acreditava em uma possível apreensão de outros campos sociais por seu método, muitos parecem esquecer. 0 foco do presente artigo consiste, pois, naquilo que se convencionou denominar, graças a Jacques-Alain Miller e outros psicanalistas, de Psicanálise Aplicada. Por meio de um estudo teórico, objetiva-se analisar a possibilidade ou impossibilidade de se fazer psicanálise fora dos consultórios. Especificamente, pretende-se delinear o que é a Psicanálise Aplicada e quais suas diferenças da então Psicanálise Pura, ou Psicanálise Livre, como denominada por Sigmund Freud (1918-1919/1996c).

Para tanto, o percurso utilizado será o de se estudar alguns artigos reunidos em forma de livro pela Associação do Campo Freudiano (2007), com o objetivo de analisar qual a especificidade dessa aplicação de um campo do saber específico: a psicanálise. Tomar-se-á inicialmente, contudo, outros textos psicanalíticos com a finalidade de apoio para nossa pesquisa, no sentido de ampliar a discussão proposta. Tais artigos e autores foram escolhidos graças à tradição de pesquisa que carregam consigo e à propriedade com que tratam o assunto.

Com este estudo, pretende-se, por conseguinte, fornecer à comunidade a discussão de uma leitura outra da atuação do psicanalista, além do estudo acerca do trabalho possível do psicanalista na escuta da subjetividade, na escuta do sujeito (do inconsciente), dentro das instituições e fora dos contornos clássicos do consultório. Entendemos que nosso estudo tem sua limitação no recorte próprio da pesquisa teórica - no sentido de que uma revisão dos trabalhos e conceitos desenvolvidos não permite validar por si só a psicanálise nas instituições - entretanto, esperamos que, a partir da discussão desenvolvida, cada qual que se reconheça psicanalista possa buscar a validação de seu trabalho em cada instituição, do caso a caso, na instituição em que atua.

\section{A Psicanálise Aplicada'}

Muitos parecem crer que a tentativa de se deslocar os conhecimentos psicanalíticos do consultório para as instituições é uma criação pós-freudiana. Entretanto, o próprio Freud (1922-1923/1996d, p. 268-269) certa vez afirmou que:

Qualquer estimativa da psicanálise estaria incompleta se deixasse de tornar claro que, sozinha entre as disciplinas médicas, ela possui as mais amplas relações com as ciências mentais e se encontra em posição de desempenhar um papel da mesma importância nos estudos da história religiosa e cultural e nas ciências da mitologia e da literatura que na psiquiatria.

A psicanálise, portanto, apesar de ter tido seu ponto de partida norteado pela clínica da eliminação de sintomas neuróticos, possui uma clara ligação entre esse ponto inicial e as ciências mentais. Esse ponto de ligação seria a compreensão dos processos inconscientes da mente proporcionada pela análise dos sonhos, uma vez que os mesmos mecanismos que geram os sintomas operam na mente dos sujeitos "normais" (Freud, 1922-1923/1996d, p. 269).

A psicanálise, então, pode ter certa valia na atuação com outras ciências, nas conversas de interface e nas discussões científicas. Por ter-se tornado uma ciência do inconsciente, como Freud veio a afirmar, pode ser elevada ao grau de campo do saber, capaz de se fazer presente na relação com alguns campos e na crítica a outros. Mas até onde teriam alcance as teorias e hipóteses da psicologia profunda freudiana?

Como um dos inúmeros exemplos que aqui poderiam ser citados, dessa possibilidade de empregar-se a psicanálise na discussão com outros campos do saber, tomam-se os comentários de Freud acerca de Pfister e da contribuição da psicanálise para os educadores. No prefácio ao livro de Pfister, Freud (1913/1996a) afirma que a "educação constitui uma profilaxia" tanto da neurose quanto da psicose, e questiona-se a respeito dos alcances de uma intervenção pautada na psicanálise, na época da escola, e na própria escola, para a prevenção da neurotização do sujeito.

Em vista dessa situação, surge imediatamente a questão de saber se a psicanálise não deveria ser utilizada para fins educativos, tal como a sugestão hipnótica o foi no passado. As vantagens seriam óbvias.

\footnotetext{
1 Lembrando que esse conceito, assim como Psicanálise Pura e Prática entre vários, tem suas raízes nos ensinos de Jacques-Alain Miller.
} 
O educador, por um lado, estaria preparado, por seu conhecimento das disposições humanas gerais da infância, para julgar quais dessas disposições ameaçam conduzir a um desfecho indesejável; e, se a psicanálise pode influenciar o curso tomado por tais desenvolvimentos, poderia aplicá-la antes que os sinais de um desenvolvimento desfavorável se estabeleçam (Freud, 1913/1996a, p. 356).

Ainda que oportuna, a questão da prevenção da neurose não será abordada neste estudo. De imediato, cabe refletir a respeito da possibilidade de aplicação da psicanálise enquanto método psicanalítico nas instituições. A questão da prevenção, como aponta Freud anteriormente, exigiria um estudo a parte, referindo-se à possibilidade de prevenção de algo (neurose) que é multideterminado e cujo ponto de partida está vinculado em algum "lugar" do psiquismo humano.

Mas o que da psicanálise pode ser pensado em sua aplicação? 0 que se pode fazer nas instituições, se é proposto se fazer psicanálise?

Em "Linhas de progresso na terapia psicanalítica", Freud (1918-1919/1996c, p. 173) apresenta a seguinte síntese: "Chamamos de psicanálise o processo pelo qual trazemos o material mental reprimido para a consciência do paciente". Consequentemente, se a psicanálise é um processo, pode-se pensar em desenvolver psicanálise em qualquer lugar onde um sujeito fale. Todavia se fazer psicanálise é desenvolver uma análise [quebra de componentes, como na química], a fim de se chegar a componentes de algo, e faz-se isso pela fala e escuta (associação livre e atenção flutuante), pode-se questionar se tal tarefa poderia ser levada a cabo numa instituição.

Sabemos que o consultório apresenta uma característica própria, particular, especial. Esse setting montado, e de certa forma controlado pelo analista, permite que o trabalho proposto pela psicanálise tenha um quê de ordem e segurança. Mas, se trabalhamos com o inconsciente, desejar uma ordem conscientemente estabelecida não beira à contradição? Se sim, podemos fazer psicanálise fora do consultório?

Adiante, no mesmo texto, Freud afirma que a tarefa terapêutica consiste em tornar consciente o material reprimido e descobrir as resistências. Fecha-se a questão? A psicanálise objetiva unicamente à terapêutica? E, ainda, pode-se fazer terapêutica na instituição? Por vezes, Freud se coloca a refletir acerca da possibilidade de a psicanálise, algum dia, sair do consultório e atender a massa da população, o que fala em favor de uma aplicação da psicanálise a outro ambiente, que não o consultório particular.

Vamos presumir que, por meio de algum tipo de organização, consigamos aumentar os nossos números em medida suficiente para tratar uma considerável massa da população. [...] haverá instituições ou clínicas de pacientes externos, para as quais serão designados médicos analiticamente preparados, de modo que homens que de outra forma cederiam à bebida, mulheres que praticamente sucumbiriam ao seu fardo de privações, crianças para as quais não existe escolha a não ser o embrutecimento ou a neurose, possam tornar-se capazes, pela análise de resistência e de trabalho eficiente (Freud, 1918-1919/1996c, p. 180).

No entanto, é o próprio Freud (1918-1919/ 1996c) quem anuncia a advertência: se algum dia essa instituição chegar a existir, muito da técnica psicanalítica deverá ser repensada. Para o autor, a técnica da psicanálise deveria, então, adaptar-se às novas condições. Cabe, aqui, enfatizar uma diferenciação entre método psicanalítico, estrutura teórica da psicanálise e instrumentação técnica. 0 que deveria ser repensado e adaptado são as técnicas, não o método nem a estrutura teórica.

O setting, como nos questionamos anteriormente, faz parte desse arcabouço técnico. É algo que pode ser modificado, então? Pode-se abrir mão de algo que é tão próprio da psicanálise, o consultório, o divã e todo o imaginário social acerca desses símbolos, construído ao longo desses cem anos de psicanálise, e mesmo assim chamar a atuação nas instituições de psicanálise?

Ademais, nosso autor afirma que:

É muito provável, também, que a aplicação em larga escala da nossa terapia nos force a fundir o ouro puro da análise livre com o cobre da sugestão direta. [...] No entanto, qualquer que seja a forma que essa psicoterapia para o povo possa assumir, quaisquer que sejam os elementos dos quais se componha, os seus ingredientes mais efetivos e mais importantes continuarão a ser, certamente, aqueles tomados à psicanálise estrita e não tendenciosa. (FREUD, 19181919/1996c, p. 181).

Quais seriam esses elementos, ou melhor, quais os ingredientes mais efetivos e importantes que devem, na Psicanálise Aplicada, ser tomados da Psicanálise Pura, ou Livre? Freud não disse, mas pode-se lançar 
a hipótese de que esses ingredientes seriam o corpo teórico e o método psicanalítico em si. 0 próprio Freud não chegou a por em prática essa ideia, a fim de trabalhar com a psicanálise fora dos consultórios, porém, cabe lembrar, empolgou-se com a iniciativa, não concluída, do Dr. Anton von Freund.

Então, se empolgado estava com a ideia de transportar a psicanálise para fora do consultório, pode-se afirmar que a incentivara e confiara em sua eficácia, além de autorizá-la. Em 1920, no breve texto com título homônimo ao nome de seu colega, Freud (1922-1923/1996b, p. 283) confirma que:

0 Dr. Anton von Freund, [...] quando, durante os seus últimos anos, veio a conhecer a psicanálise, ela pareceulhe prometer a realização de seus dois grandes desejos. Impôs-se a tarefa de ajudar as massas pela psicanálise e de fazer uso dos efeitos terapêuticos dessa técnica médica, que até então estivera apenas a serviço dos ricos, a fim de mitigar os sofrimentos neuróticos dos pobres.

A ideia do Dr. Von Freund era desenvolver um instituto, em Budapeste, no qual a análise deveria, por convenção, ser praticada, ensinada e fosse acessível à massa da população. Também, deveriam ser formados por meio desse instituto médicos que, depois, seriam preparados para tratar neuróticos numa "clínica de ambulatório" (Freud, 1915/1996b, p. 284). Era o que se pode pensar de uma aplicação da psicanálise ao ambulatório que apresenta, com certeza, um mecanismo de funcionamento diferente do consultório particular.

Fato é que muitos psicanalistas de outrora e de atualmente propõem-se a desenvolver a intitulada Psicanálise Aplicada. E, para os propósitos deste artigo, cabe refletir a respeito dessas atuações, em diferentes campos e em diferentes tempos.

\section{Possibilidades de aplicação da psicanálise}

Muitos exemplos poderiam ser aqui citados do que pode ser considerada como uma aplicação da psicanálise a outras dinâmicas que não o consultório e a análise estritamente concebida.

Em se tratando do meio educativo, acadêmico, ou mais especificamente da aplicação em Educação
Terapêutica, pode-se citar a experiência da Escola Experimental de Bounneuil-sur-Marne (Mannoni, 1988), na França; a experiência do Lugar de Vida Centro de Educação Terapêutica (Kupfer, 1999) em São Paulo, vinculado ao Instituto de Psicologia da USP; e a experiência da Associação Serpiá, na cidade de Curitiba. ${ }^{2}$

Em se tratando do atendimento a escolares fora da escola, podemos citar o livro de Bergès, BergèsBounes, \& Calmettes-Jean (2008), intitulado $O$ que aprendemos com as crianças que não aprendem, e o trabalho de Bernardino \& Kupfer (2008).

Finalmente, em relação à possibilidade de atendimento de um psicanalista no hospital, citamos o livro $O$ que pode um analista no hospital? (Moretto, 2002), e a Tese de Doutorado da psicanalista Nadja Pinheiro (2003).

Mas então, o que se faz, e o que se pode fazer, quando se faz Psicanálise Aplicada? Mezan (2002, p. 318) entende essa expressão, Psicanálise Aplicada, como sendo "a parte da psicanálise que procura focalizar, em produtos humanos que não surgem no consultório, os mecanismos típicos que conhecemos", mecanismos que podem ser elencados como os sintomas, os sonhos, os atos falhos, as inibições, etc. A Psicanálise Aplicada, então, seria o ouvido do psicanalista servindo dentro de outras paredes, ou fora das paredes do consultório. Uma psicanálise, nas palavras de Mezan, que seja "capaz de ler, nas maiúsculas da cultura, coisas que podem ter validade também nas minúsculas da vida psíquica individual" (Mezan, 2002, p. 319).

Entretanto, apesar de bem definida, a Psicanálise Aplicada parece, pelo menos para Mezan, algo como o gêmeo mau da Psicologia Profunda. E não é de se espantar, tendo em vista sua proposição de uma dinâmica distinta daquela inicialmente estabelecida por Freud para a atuação dos psicanalistas. Essa proposta modifica pontos de vista, implica em ajustes na atuação e em se ver diante de novas angústias referentes a novos limites na prática. Como observa Mezan (2002, p. 319):

[...] poucos são os que gostam da Psicanálise Aplicada. Os próprios analistas às vezes se sentem algo envergonhados, pois consideram que o material diretamente

2 Para maiores detalhes, acessar o site da associação: http://www.serpia.org.br/. 
clínico é mais nobre; esse desprezo continua por parte dos praticantes de outras disciplinas, que não gostam muito da intromissão dos analistas na sua seara.

"Isso" posto, cabe perguntar: Como se faz Psicanálise Aplicada? Pode-se levar um divã para a escola, para a empresa, ou para o espaço de um centro de educação terapêutica? Logo o divã, símbolo máximo socialmente aceito da psicanálise e dos psicanalistas! Existe psicanálise sem divã? Concordamos com Mezan de que o ponto central refere-se à compreensão de quais - e em que medida - instrumentos classicamente forjados por Freud possam ser utilizados ou devam ser revistos; ou mesmo, que outros devam ser criados.

Di Ciaccia (2007) pondera que a tentativa dos psicanalistas trabalharem fora dos consultórios não é recente. Seja por rebeldia contra o pai ou por vislumbrarem uma saída outra para uma proibição (que, diga-se de passagem, como vimos no início deste estudo, nunca aconteceu, muito pelo contrário) de que se faça psicanálise fora das paredes protegidas do consultório, ao longo da história, alguns psicanalistas têm se comprometido com essa escuta nas maiúsculas da cultura. Entretanto, para Di Ciaccia, a prática mesma da Psicanálise Aplicada precisa ser sempre inventada. Como Mezan afirmou, os instrumentos devem ser repensados e redimensionados, a fim de que se possam atingir os objetivos.

Matet e Miller (2007, p. 1-2), na apresentação ao livro Pertinências da Psicanálise Aplicada, afirmam que não existe Psicanálise Aplicada sem a Psicanálise Pura. Para ambos, "passou o tempo da figura mítica do psicanalista limitando seu campo de atividade às paredes de seu consultório, para convencer de sua devoção à causa privada de seus analisantes". Assim conduzindo, abrem espaço para se pensar que, atualmente, o lugar do psicanalista ganha novo contorno, novos entornos. Não mais as paredes que o contornavam junto ao divã. Mas... por que essa saída dos consultórios? Para os autores,

hoje, os psicanalistas dizem em que sua formação os leva a fazer da psicanálise o instrumento pertinente da leitura dos casos, fazendo contraponto e contrapeso aos desenvolvimentos científicos da medicina e à proliferação das psicoterapias. Eles foram coagidos pela necessidade: o sucesso da psicanálise na multiplicação das práticas "psi" assinala sua dissolução em um culto da escuta que, longe de permitir ao sujeito advir, usa da fala para melhor garantir que ele não seja ouvido (Matet \& Miller, 2007, p. 2).

Em outras palavras, a saída dos psicanalistas do consultório se faz num momento específico e motivado pela ética da psicanálise. Momento em que a multiplicação das práticas "psi" toma corpo e vida nos inúmeros campos sociais para falar de um sujeito que não pode falar por si, ou que não é permitido que fale por si. É como se atualmente a sociedade necessitasse que a "ciência psi" falasse da subjetividade, falasse dos sujeitos, sobre os sujeitos, mas sem ouvir esses sujeitos.

Nesse novo ambiente, seja escola terapêutica, clínica, ambulatório ou escola regular,

um primeiro ponto se destaca: encontrar um analista não exige necessariamente o cerimonial do tratamento. Pôr em jogo a transferência e o que nela se interpreta não exige nenhum standard, tampouco um setting. Implica pôr em jogo o corpo por meio da fala interpretante, através desse artifício singular que se assemelha ao amor. A formalização da transferência, a partir do sujeito suposto saber, [...], constitui o ponto de partida dessa orientação (Matet \& Miller, 2007, p. 3-4).

Com esse entendimento, não se desprezam, mas não se tornam necessários, os instrumentos técnicos da psicanálise elaborados por Freud. Mas pode se pensar assim? Estaria desconsiderado, nesse sentido, o mecanismo do dinheiro (pois nessas instituições não existe o pagamento formal do sujeito ao psicanalista); estaria desconsiderado o mecanismo do tempo (pois as análises intermináveis e termináveis dos consultórios perderiam tal característica); estaria desconsiderado o divã (pois não se entra com um desses nas instituições de ensino, por exemplo)? E, apesar de todas essas desconsiderações, poder-se-ia ainda, essa outra prática, se considerar psicanálise?

O que, de fato, é a psicanálise? Sabemos que Freud citou vários pontos para que determinada prática fosse considerada psicanálise. Sem nos propormos a uma pesquisa exaustiva, podemos relembrar de imediato da questão da transferência, da resistência, do objetivo de tornar consciente conteúdos inconscientes e de levar o eu a subjetivar o isso.

Para Guéguen (2007, p. 18-19),

[...] a psicanálise começa quando, sob transferência, o sujeito se submete à decifração das formações de seu 
inconsciente [...]. Portanto o fato de haver análise não depende nem de sua duração, nem do lugar, nem do ritual, mas sim do tipo de operação que se efetua sobre o gozo, graças aos poderes da fala: para nós, o enquadre é feito para servir à análise, e não que a análise seja feita para servir ao enquadre. Isso quer dizer que não há obstáculo para que a psicanálise aplicada se pratique em lugares diferentes do consultório do analista, por exemplo, na instituição.

O importante, para o autor, é a operação que se efetua em uma análise, ou nas palavras de Freud (19181919/1996c) 'o processo da psicanálise'; e não os itens ou instrumentos dos quais ela se usa. A Psicanálise Aplicada, então, tornar-se-ia possível quando o psicanalista atua visando ao processo, aos meios e aos objetivos da psicanálise, sem se prender aos instrumentos com os quais esse processo foi inicialmente elaborado. 'O resto é resto', como diria Lacan.

Mas como é o trabalho em si na instituição? Se for possível aplicar a psicanálise à instituição, qual instituição se faz com a psicanálise?

\section{A instituição aplicada}

Retomando o último questionamento aqui elencado, faz-se necessário pensar em qual instituição se fala quando se fala em Psicanálise Aplicada. Quais seriam suas características e onde poderia ser aplicada? Concordamos com Alexandre Stevens (2007, p. 77), quando afirma que se deve produzir uma instituição que se pregue como instituição do caso a caso; instituição do caso particular, do sintoma singular. 0 que deve guiar o psicanalista nessa instituição do caso a caso é, então, a realidade psíquica, feita de linguagem, como nos lembra o autor. "É preciso produzir uma instituição tal que permita a existência, no interior dela mesma, de tantas instituições quantos forem os sujeitos que as habitam".

Nesse fluxo de pensamento, com a Psicanálise Aplicada cada caso atendido se torna uma instituição. E ora entende-se instituição no sentido atribuído por Guirado (2005), como sendo uma prática discursiva, uma prática que se repete e, repetindo, legitima-se; autoriza-se pela repetição de seus atores. Na relação a dois, psicanalista-sujeito, e na repetição dessa relação, de suas normas e leis implícitas e explícitas, algo se legitima, e, legitimando-se, institui-se. Poderia se fazer psicanálise na instituição, uma vez que esse ambiente seria apenas o arcabouço físico para a instituição do único que ali se atualiza?

Stevens (2007, p. 78) continua seu texto apontando para o lugar de não saber do psicanalista. Ele afirma que "é preciso furar a instituição, ou seja, colocá-la do lado do não saber". Nesse sentido, a posição do psicanalista em uma instituição estaria consoante à possibilidade de proporcionar o surgimento do sujeito. Um sujeito do inconsciente, um sujeito de desejo. Para o autor, ao contrário da posição do psicanalista, a instituição é orientada por um significante-mestre da civilização. Significante-mestre aqui entendido como a palavra que comporta um saber e uma Verdade com $\mathrm{V}$ maiúsculo. Uma Verdade à qual não cabe dúvida nem questionamento. Nesse sentido, segundo o autor, ao psicanalista, atuando na instituição, caberia o difícil papel de, ao mesmo tempo, não se colocar a serviço do mestre, tampouco opor-se a ele. Não se deve ser contramestre, no sentido de dizer o quanto a instituição está errada, pois, se assim o faz, ele é implicitamente obrigado a dizer como seria o certo, e o Bem Supremo, ele não o tem, como nos lembra sempre Lacan. Para Stevens, o trabalho do psicanalista deve ser furar o significante-mestre da instituição, ou seja, na instituição do caso a caso, do particular, furar as certezas do mestre-instituição que rege, ou tenta reger, um futuro ideal para aquele sujeito; e assim, favorecer o advento de um desejo próprio e singular do sujeito único que ele ouve.

Mas como realizar isso quando o psicanalista é ele próprio institucionalizado, em uma instituição que prega o contrário do caso a caso $?^{3}$ Como pensar o particular? O subjetivo? A subjetividade heterogênea do sujeito? Eis, talvez, o papel do psicanalista na instituição.

Para Bosquin (2007, p. 175), a instituição se torna psicanalítica quando se propõe "como um lugar vazio para o sujeito". Em outras palavras, a instituição formada pelo caso a caso, pela relação psicanalista-sujeito, torna-se uma relação analítica quando o psicanalista se propõe um lugar vazio, um não saber, para o sujeito, a fim de que esse sujeito possa elencar mudanças próprias, desenvolvidas e reconhecidas por si mesmo, para sua vida.

3 Como, por exemplo, na atuação em atendimento individual a alunos, em uma escola - experiência de um dos autores desse artigo. 


\section{0 psicanalista aplicado}

Parece que, de acordo com os autores anteriormente reportados, pode-se pensar o trabalho do psicanalista como a reflexão sobre o caso a caso, subvertendo o significante mestre da civilização, e da instituição, a fim de dar voz ao sujeito.

Contudo não se trata de ser contramestre, como vimos, tampouco de dar livre vazão ao desejo e às pulsões. Mas de dizer sim para algo que pode favorecer a pulsão de vida, tirando o sujeito de repetições destrutivas a si mesmo, como discussões descabidas com superiores, reprovações persistentes na escola, dificuldade de ascensão na carreira, etc.

Ademais, para Guéguen (2007), mesmo quando não existir uma transferência de trabalho entre a instituição e a psicanálise, torna-se possível praticar a Psicanálise Aplicada. Nesse sentido, o papel do psicanalista na instituição, quando trabalhando de uma maneira aplicada à instituição, ${ }^{4}$ deve ser tomar o papel de um semblante, um lugar quase-que-vazio, ou suposto-vazio, que quebra a lógica do significante-mestre. 0 psicanalista na instituição deve, dessa forma, ser semblante, tomar um lugar onde faz crer que há, o que de fato não há (Rubião, 2006). Ele assume uma posição, que pode ser vista como representante da instituição, para questionar e colocar questões a respeito das certezas naturais dessa instituição, com o intuito de desconstruir cristalizações e promover reflexões que visem a construir novos posicionamentos do sujeito perante sua vida.

Como vimos, os autores são uníssonos em dizer que o lugar do psicanalista em uma instituição é um lugar de não saber, de uma não especialização. Para Rabanel (2007, p. 87), a ênfase deve ser "posta no sujeito e na falta, na não especialização e em uma certa desconfiança para com o saber"; e, em compensação, se deve afirmar "uma confiança no desejo. Sim, uma ética do desejo".

Parece que se pode postular, portanto, que a posição do psicanalista aplicado é a posição do não especialista, do faltante em relação ao saber do mestre, que, por assim agir, possibilita o sujeito, e o desejo, advir. 0 trabalho psicanalítico na instituição, segundo Kusnierek (2007), visa a uma mudança do regime do gozo. Por meio da fala, proporcionar uma elaboração desse regime de satisfação, por vezes mortífero e associal, um regime que não constrói e promove a repetição de algo que faz o sujeito sofrer (como visto anteriormente, a repetição de um fracasso escolar, repetidas discussões com superiores na empresa, etc). Contudo Kusnierek (2007) faz uma advertência, que merece ser considerada, acerca da impossibilidade de se antecipar a origem, a configuração ou os efeitos de um ato. Mesmo assim, tal ato seria necessário para a manutenção do desejo de saber, ainda que este não diga respeito ou garanta validade em relação a todos. Por conseguinte, pode-se pensar que a psicanálise, por ser um processo, não pode ser certa a priori. Não se tem como dizer que será feito psicanálise, senão dizer que ela foi ou não realizada, uma vez que, não se sabe de antemão o que será um ato psicanalítico. 0 ato psicanalítico, nesse contexto, pode ser descrito como explicado por Víctora (2006, p. 1) ao retomar Lacan:

[...] um ato tem sempre a ver com a palavra e com o corte. Como palavra - significante - ele é representante do sujeito. Como corte, ele é uma função, uma operação no sentido matemático do termo. Sua topologia é precisa: ela envolve um vazio. 0 psicanalista, por sua vez, também é colocado em um lugar vazio - lugar de desejo para o analisando. A transferência seria uma forma de atuação e de atualização do inconsciente. Assim, o ato psicanalítico pode ser considerado como criador do sujeito do desejo.

Disto resulta que o ato psicanalítico é o ato que induz à mudança: um corte no discurso repetido do sujeito. Um apontamento para outra direção possível de ser tomada, com o fim de modificar algo. Neste sentido, como observa a autora, difere do ato médico, marcado como a voz do mestre, que tudo sabe e tudo tem certeza.

É esse ato, portanto, o que deve ser desenvolvido pelo psicanalista aplicado. Na instituição, é isso que o psicanalista pode buscar. Um ato incompleto que venha a "fazer furo nos significantes-mestres". É fazer corte, ser local de não saber diante do sujeito. Local este que possibilita, por parte do sujeito, desenvolver algo novo em relação ao seu próprio desejo.

\footnotetext{
4 Nesse artigo, diferencia-se essa posição da posição de um psicanalista, tendo a instituição como sujeito de sua intervenção, como propõe Bleger (1984), por exemplo.
} 


\section{Considerações finais}

Ao longo deste artigo, estudou-se o que se convencionou chamar de Psicanálise Aplicada. Partiuse de reflexões freudianas acerca da possibilidade de expansão do método e das teorias psicanalíticas para outros domínios que não o consultório e terminou-se estudando pontuações teóricas de psicanalistas a respeito da atuação em instituições.

Entretanto, apesar de seguir um caminho que leva à conclusão de poder-se afirmar uma Psicanálise Aplicada em instituições, muitos psicanalistas ainda relutam (como mostra Mezan) em aceitar tal colocação. Nessa relutância, encontra-se uma pertinente afirmação, que pondera a psicanálise como uma metodologia e técnica própria, e que possui um objeto particular e um domínio singular. Desvirtuar qualquer um desses pontos seria perder sua especificidade e tal prática já não mais poderia ser considerada psicanálise.

É fato que Freud, por inúmeras vezes em seus escritos, tentou promover certa redução do que seria a psicanálise a algumas 'regras de ouro'. Uma dessas vezes foi descrita nesse artigo, anteriormente. Entretanto, parece que não se chega, ou melhor, não se pode chegar a um consenso entre os psicanalistas de algo conclusivo acerca de quais elementos são obrigatórios para que tal prática seja denominada psicanálise. Uns dizem que, se se tem em vista conceitos básicos como o inconsciente, o complexo de Édipo e a transferência, a prática pode ser denominada psicanálise; outros apontam que apenas isso não basta, mas o setting e os instrumentos técnicos devem ser tais como descritos por Freud; outros, ainda, dizem que o setting deve servir à psicanálise e não o contrário.

Enfim, a prática da Psicanálise Aplicada, ou a aplicação da psicanálise nas maiúsculas da sociedade, ainda promoverá grandes discussões no campo do saber psicanalítico e não será esse estudo a finalizar tal discussão. Seu intuito é menos abrangente, limitando-se a refletir sobre a possibilidade de se fazer psicanálise em uma instituição. A revisão teórica aponta para algo importante que convém retomar. 0 psicanalista na instituição só pode trabalhar como psicanalista se tiver em vista o caso único, o sujeito particular, a subjetividade que, por vezes, é relegada. Relegada em nome de uma padronização dos comportamentos e, quiçá, dos desejos, como muitos autores já disseram.
Por conseguinte, e finalizando, se se pode concluir algo deste estudo, então, é que se há Psicanálise Aplicada, ela só pode existir na aplicação do caso único. Na possibilidade de se ouvir o sujeito que fala e deseja, na instituição.

\section{Referências}

Associação do Campo Freudiano (Org.). (2007). Pertinências da psicanálise aplicada: Trabalhos da escola da causa freudiana. Rio de Janeiro: Forense Universitária.

Bergès, J., Bergès-Bounes, M., \& Calmettes-Jean, S. (Org.). (2008). 0 que aprendemos com as crianças que não aprendem? Porto Alegre: CMC.

Bernardino, L. M. F., \& Kupfer, M. C. M. (2008, setembro). A criança como mestre do gozo da família atual: desdobramentos da "pesquisa de indicadores clínicos de risco para o desenvolvimento infantil". Revista Mal-estar e Subjetividade, 8(3), 661-680.

Bleger, J. (1984). Psico-higiene e psicologia institucional. Porto Alegre: Artes Médicas.

Bosquin, P. (2007). Escreve para mim... um corpo!. In Associação do Campo Freudiano (Org.). Pertinências da psicanálise aplicada: Trabalhos da escola da causa Freudiana (pp. 174-179.). Rio de Janeiro: Forense Universitária.

Di Ciaccia, A. (2007). Inventar a psicanálise na instituição. In Associação do Campo Freudiano (Org.). Pertinências da psicanálise aplicada: Trabalhos da escola da causa Freudiana. Rio de Janeiro: Forense Universitária.

Freud, S. (1996a). Introdução a The Psycho-analytic Method, de Pfister. (Publicado originalmente em 1913).

Freud, S. (1996b). Os instintos e suas vicissitudes. Rio de Janeiro: Imago. (Publicado originalmente em 1915).

Freud, S. (1996c). Linhas de progresso na terapia psicanalítica. Rio de Janeiro: Imago. (Publicado originalmente em 1918-1919).

Freud, S. (1996d). Dois verbetes de enciclopédia. Rio de Janeiro: Imago. (Publicado originalmente em 1922-1923). 
Guéguen, P. (2007). Quatro pontuações sobre a psicanálise aplicada. In Associação do Campo Freudiano (Org.). Pertinências da psicanálise aplicada: Trabalhos da escola da causa freudiana (pp. 17-26.). Rio de Janeiro: Forense Universitária.

Guirado, M. (2005). 0 caso do psicodiagnóstico: Um estudo institucional. Psicologia USP, 16(4), 11-32.

Kupfer, M. C. (1999). Freud e a Educação, dez anos depois. Revista da Associação Psicanalítica de Porto Alegre, (16), 15-26.

Kusnierek, M. (2007). Pertinências e limites da prática entre vários. In Associação do Campo Freudiano (Org.). Pertinências da psicanálise aplicada: Trabalhos da escola da causa freudiana (pp. 161-166). Rio de Janeiro: Forense Universitária.

Mannoni, M. (1988). Educação impossível. Rio de Janeiro: Francisco Alves.

Matet, J., \& Miller, J. (2007). Apresentação. In Associação do Campo Freudiano (Org.). Pertinências da psicanálise aplicada: Trabalhos da escola da causa freudiana (pp. 1-5). Rio de Janeiro: Forense Universitária.

Mezan, R. (2002). Interfaces da psicanálise. São Paulo: Companhia das Letras.
Moretto, M. L. T. (2002). o que pode um analista no hospital? São Paulo: Casa do Psicólogo.

Pinheiro, N. N. B. (2003). Uma casa com paredes de cristal: A clínica psicanalítica no ambulatório hospitalar. Tese de Doutorado, Departamento de Psicologia, Pontifícia Universidade Católica do Rio de Janeiro, Rio de Janeiro.

Rabanel, J. (2007). Nonette, uma instituição do RI ${ }^{3}$. In Associação do Campo Freudiano (Org.). (2007). Pertinências da Psicanálise Aplicada: Trabalhos da Escola da Causa Freudiana (pp. 86-90). Rio de Janeiro: Forense Universitária.

Rubião, L. L. (2006). A comédia e a ruptura dos semblantes: Notas sobre as "nuvens", em Lituraterra. Ágora, 9(2), 259-271.

Stevens, A. (2007). A instituição: Prática do ato. In Associação do campo freudiano (Org.). Pertinências da psicanálise aplicada: Trabalhos da escola da causa freudiana (pp. 76-85). Rio de Janeiro: Forense Universitária.

Víctora, L. G. (2006, agosto). Editorial. Correio da Associação Psicanalítica de Porto Alegre, (149), 1. 
